\title{
Progress in elaboration of nonisocyanate polyurethanes based on cyclic carbonates
}

\author{
O. Figovsky, L. Shapovalov, A. Leykin, O. Birukova, R. Potashnikova \\ Polymate Ltd. - International Nanotechnology Research Center, Migdal HaEmek, Israel \\ E-mail address: contact@polymateltd.com
}

\begin{abstract}
In the article is given a review on synthesis and application nonisocyanate polyurethanes based on cyclic carbonate oligomers. Nonisocyanate polyurethane (NIPU) networks are obtained by reaction between the polycyclic carbonate oligomers and aliphatic or cycloaliphatic polyamines with primary amino groups. This forms a crosslinked polymer with $\beta$-hydroxyurethane groups of different structure - polyhydroxyurethane polymer. One of the most interesting derivatives of unsaturated fatty compounds is epoxidized triglyceride oils (ETO), particulary epoxidized soybean oil (ESBO). Until now, ESBO is primarily used as plasticizers for polyvinyl chloride, chlorinated rubber and polyvinyl emulsions to improve their stability and flexibility. Also there are numerous useful derivatives of ETO. Among the various materials, products of reactions of ETO and carbon dioxide $\left(\mathrm{CO}_{2}\right)$ deserve special attention. A basic composition and a technique for mixing and foaming were developed for insulating foam applied by spraying, the material being based on the use of the synthetic raw materials. UV-curable concrete floor coatings provide a durable, high-performance and eco-friendly solution. These thin-film coating systems cure instantly, thereby minimizing the downtime of any facility. Other benefits of these coatings include excellent chemical resistance, easy cleanability, little odor, and the ability to coat in cold conditions; Fig. 3, Tabl. 3, Ref. 39.
\end{abstract}

\section{Keywords}

nonisocyanate polyurethanes; cyclic carbonate oligomer; coatings, foam; adhesives

\section{INTRODUCTION}

The polyurethane (PU) market today amount to about $5 \%$ of the total polymer market and the worldwide consumption of PU has increased steadily. $80 \%$ of PU productions come to resilient and rigid foams and $20 \%$ come to solid PU (elastomers, coatings, adhesives, etc.) [1].

At the same time, conventional PU have an inherent weakness depending on their molecular composition. Van der Waals forces mainly sets physically and mechanically properties of PU. The strength of these bonds is significantly lower in energy, however [1]. Therefore PU unsatisfactorily stands up to the dynamic load, especially at elevated temperature.

Also, the involvement of toxic components, such as isocyanates, in the fabrication process renders PU production extremely toxic and dangerous.

People exposed to isocyanates can develop a range of short-term health problems. Isocyanate exposure can lead to long-term asthma and dermatitis if individuals become sensitized. Sensitization is a condition in which the breathing or skin conditions can return with increasing 
severity on further exposures to the original sensitizing agent or to similar substances, even at very low exposures [2].

In the field of PU preparation for a long time are being sought nonisocyanate sources of polyurethanes. Fundamentals of chemistry and technology of nonisocyanate polyurethanes (NIPU) on the base of polycyclic carbonates and polyamines were developed in detail by O. Figovsky in 60-th [3]. Recently some reviews devoted to synthesis of cyclic carbonates and NIPU were presented [4-6]. In these works the positives of NIPU were described in detail.

Since NIPU is obtained without using of highly toxic isocyanates, the process of synthesis is a fairly reliable in terms of safety and environmental impact - in contrast to conventional polyurethanes. Moreover, NIPU is not sensitive to moisture in the surrounding environment. Formed hydroxyl groups at the $\beta$-carbon atom of the urethane moiety promote adhesion properties. Plurality of intra- and intermolecular hydrogen bonds $[7,8]$ as well as no contamination of unstable biuret and allophanate units [9] seems to be responsible for increasing of thermal stability and chemical resistance to non-polar solvents.

However, for more than 50 years since the first publication in this field, NIPU still do not have a sufficiently broad application. This can be explained by certain features of these materials. Cyclic carbonate (CC) groups interact with aliphatic and cycloaliphatic polyamines at ambient temperatures slower than isocyanates with hydroxyl groups. The rate of this reaction is comparable to the rate of curing epoxy resins (ER) with amines. At the same time, the CC react only with primary amino groups, in contrast to the ER, which react with primary and with secondary. This results in a decrease in crosslinking density of the polymer network.

Many well-known companies and research centers in the world intensive develop new methods for the synthesis of cyclic carbonates and compositions thereof. Leading positions in the development of non-isocyanate materials held research center Polymate Ltd. During 2012 year were provided the following works:

It were elaborated 6 new paint's compsition, 4 new flooring's compositions, 2 new curing agents, new foam and 3 new composition of UV curable coatings;

It were tested 8 newel formulations, including non-amine hardener, waterborne composition and pure NIPU composition.

It were prepared for testing 150 samples at 50 companies.

For further developments in the field of polyhydroxyurethanes, we have carrying out the following elaboration:

1. Creation of production of polyfunctional cyclocarbonates, development of optimal technology and equipment:

- carbonized vegetable oils and terpenes;

- carbonized aliphatic compounds, including chlorinated ones;

- carbonized polyfunctional silicones.

2.Development of waterborne HNIPU formulations.

3. Development of NIPU formulations for sealants and adhesives.

4. Development of production of amines modified with hydroxyurethane groups.

5. Elaboration of non-amine RT curing agents for oligomer compositions.

6. Development of self-extinguishing compositions of HNIPU.

7. Development of silicone-based HNIPU.

8. Development of NIPU and HNIPU-based foams.

9. Development of formulations for UV-cured compositions. 


\section{POLYHYDROXYURETHANES}

Nonisocyanate polyurethane (NIPU) networks are obtained by reaction between the polycyclic carbonate oligomers and aliphatic or cycloaliphatic polyamines with primary amino groups [4]. This forms a crosslinked polymer with $\beta$-hydroxyurethane groups of different structure - polyhydroxyurethane polymer. The model scheme of the two options $\beta$-hydroxyurethane fragments of polymer chains formed in the case of difunctional starting materials is shown in Figure 1.

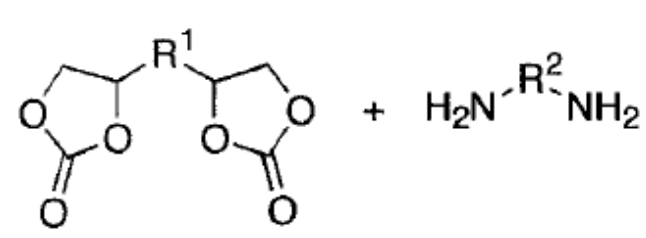

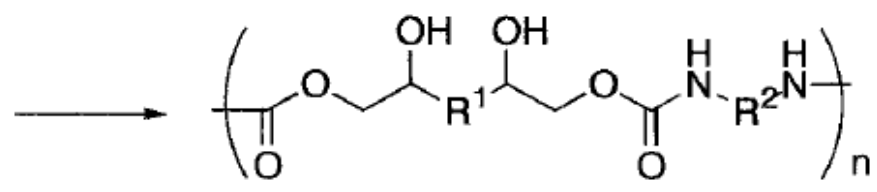

A

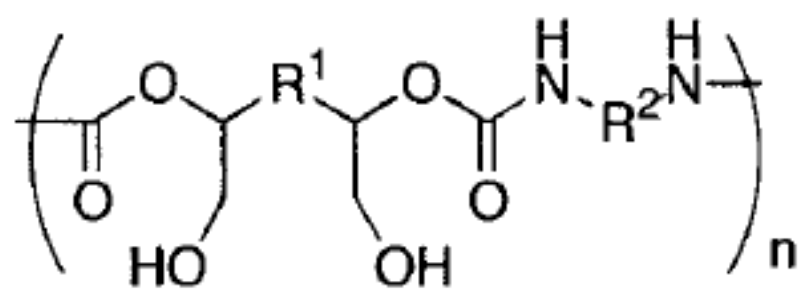

B

Fig. 1. $\beta$-hydroxyurethane moieties of nonisocyanate polyurethanes: A - with secondary hydroxyl groups; B - with primary hydroxyl groups

Usually polyhydroxyurethane polymer is not enough water resistant due to plurality of hydroxyl groups. But it is possible to prepare water resistant materials in some formulations. For example, on the base of acrylic epoxy oligomers was prepared cyclocarbonate acrylic polymers with high water and weather stabilities. It was elaborated paint with curing temperature $110^{\circ} \mathrm{C}, 2-$ 3 hour. Unfortunately we need to use solvents for this composition [4].

Great problem of the NIPU technologies is the practically absence of commercially available multifunctional cyclic carbonates. In this regard, Bernard (Rhodia) propose a method for preparing polyhydroxy-urethanes, said method comprising reacting at least one compound (1) having a cyclic carbonate functional group and at least one hydroxyl functional group; at least one compound (2) having at least one linear carbonate functional group; at least one compound (3) having at least one primary or secondary amine functional group [10].

An object of this invention is to propose predominantly aqueous formulations on the base of polyfunctionalized polyhydroxy-urethane intermediates, as well as a method for preparing said formulations and their uses, especially for producing coatings, adhesives, and others.

However, the described process is very complicated and time-consuming, requires large amounts of organic solvents, and formulations for practical application in most cases require the use of isocyanate-containing components.

Moeller, et al. (Henkel) also describe the bonding agent system that contains a component (A) carrying at least two cyclic carbonate groups and a component (B) carrying at least two amine 
functional groups to prepare a two-component NIPU adhesive [11]. But in this case also component (A) comprises a reaction product of hydroxyl group-containing cyclic carbonate with an isocyanate group-containing polyurethane prepolymer.

Recently, the company Polymate works on the synthesis of aliphatic multifunctional cyclic carbonates from corresponding epoxies and carbon dioxide and NIPU based on them. Authors tested some compositions of synthesized in the laboratory polyfunctional carbonates, namely trimethylol propanetricyclocarbonate (TMPTCC) and chlorine-contained aliphatic tricyclocarbonates (on the base of chlorine-contained aliphatic epoxy resins Oxilin ${ }^{\mathrm{TM}}$ ) and various diamines: 2-methylpentamethylene diamine (MPMD) - Dytek ${ }^{\circledR}$ A, Invista Co.; metaxylenediamine (MXDA) - Mitsubishi Gas Chem. Co.; polyetheramine Jeffamine EDR-148 Huntsman Co.; diethylenetriamine (DETA) - D.E.H. ${ }^{\text {TM }}$ 20, Dow Chemical Co..

Some properties of these materials are shown in Table 1:

Table 1. Some of the results significantly higher than previously achieved level and offer good prospects for their practical use. Further elaboration will be provided.

\begin{tabular}{|l|l|c|c|c|}
\hline \multicolumn{1}{|c|}{ CC } & \multicolumn{1}{|c|}{ Amine } & $\begin{array}{c}\text { Tensile Strength, } \\
\text { MPa }\end{array}$ & Elongation, \% & Water absorption \\
\hline TCCTMP & MPMD & $33-47$ & $3.3-3.8$ & $\mathrm{n} / \mathrm{a}$ \\
\hline CC Oxilin 5 & MXDA & 18 & 4 & $\mathrm{n} / \mathrm{a}$ \\
\hline $\begin{array}{l}\text { CC Oxilin } \\
\text { 6B }\end{array}$ & EDR-148 & 0.8 & 10 & 4.0 \\
\hline CC Oxilin 6 & DETA & 1.6 & 16 & $\mathrm{n} / \mathrm{a}$ \\
\hline
\end{tabular}

\section{HYBRID NONISOCYANATE POLYURETHANES}

Currently in the coatings industry cyclic carbonate raw materials often suggest to use in hybrid epoxy-hydroxyurethane compositions [5]. Use of such systems assumes preliminary receiving of the adducts of the cyclic carbonates and amines. These adducts (also named as aminourethanes) contain amine, urethane and hydroxy groups and serve as hardeners for various oligomer compositions. Such compositions, named as Hybrid NIPU (HNIPU), are well known in the art. Mainly they relate to waterborne epoxy compositions.

Muller-Frischinger (Huntsman Co.) [12a] describes a curable composition comprising: a) mixture of an epoxy resin a cyclic carbonate, and b) as curing agent a hybrid hardener, whereby said hardener is a blend of b1) an aminic compound, and b2) a dicyclopentadiene-phenol based Novolac. Later Muller-Frischinger et al. disclose a curable composition comprising an epoxy resin and a hybrid hardener; wherein said hybrid hardener is a blend of adduct of amines or amidoamines and monocyclic carbonates (in particular) and a polyphenol Novolac. Such compositions are useful for rapid setting and protective coatings and adhesives in application fields like civil engineering, marine, architectural and maintenance [12b]. Also researches of Huntsman Co. proposed filled compositions on the base of NIPU or HNIPU and nano-clays [13].

In this work were used some of synthesized in Polymate Ltd. cyclic carbonates (as row materials). Klopsch et al. (BASF) disclose the use of new cyclic carbonates with unsaturated bonds as reactive diluents in epoxy resin compositions [14]. It has been found that the addition just of small amounts of the new compounds to epoxy resins results in a significant increase in the reactivity of the epoxy resin composition, evident from a lower gel time following addition of a 
hardener. However, enhancing of other important properties has not been presented. MecfelMarczewski et al. (Construction Research \& Technology $\mathrm{GmbH}$ ) propose substituted cyclic carbonates - 2-Oxo-1,3-dioxolane-4-carboxylic acid and derivatives thereof. It is assumed that these compounds will be widely used in the oligomer technology [15]. Recently authors proposed compositions based on oligomer systems which contain a hydroxy-amine adducts on the base of aliphatic mono- and polycyclic carbonates (Cycloate $\mathrm{A}^{\mathrm{TM}}$ ) as hardeners [16]. This compositions used for $100 \%$ solid floorings and have high abrasion resistance and mechanical properties. Thus in the Polymate were elaborated practically used formulations on the base of HNIPU.

\section{HYDROXYURETHANE MODIFIERS}

A separate area of the NIPU-technology is use of the pure hydroxyalkyl urethane compounds. Now all known polymer compositions with hydroxyalkyl urethane monomers demand specific chemical reactions (such as transetherification, transamination, or self-crosslinking). These reactions are carried out at elevated temperatures, in the presence of organic solvents, and/or in water-dispersion media, sometimes in the presence of catalysts [5].

Recently, the authors have developed a new approach to the modification of oligomer compositions - introduction hydroxyurethane groups without chemical interaction with the major components of the polymer matrix. This approach allowed us to significantly improve a number of practically important properties of materials. Since the structure of the polymer network is not broken, other properties of the compositions are not reduced.

In our patent application [17] disclosed a novel epoxy-amine composition modified a hydroxyalkyl urethane, which is obtained as a result of a reaction between a primary amine $\left(\mathrm{C}_{1}\right)$ and a monocyclocarbonate $\left(\mathrm{C}_{2}\right)$, wherein modifier $(\mathrm{C})$ is represented by the formula in Figure 2:

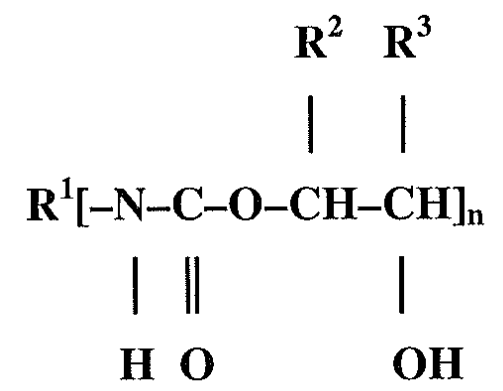

Fig. 2. Basic formula of hydroxyalkyl-urethane modifier

wherein $\mathrm{R}^{1}$ is a residue of the primary amine, $\mathrm{R}^{2}$ and $\mathrm{R}^{3}$ are the same or different and are selected from the group consisting of $\mathrm{H}$, alkyl, hydroxyalkyl, and $\mathrm{n}$ satisfies the following condition: $\mathrm{n} \geq 2$. Diluents, pigments and additives can be used. The influence of the new modifier primarily affects a significant acceleration of the curing process, as well as increased of abrasion resistance. Doping with the hydroxyalkyl-urethane modifier (HUM) impart to the cured composition superior coating performance characteristics (pot-life/drying, strength-stress, bonding, appearance, resistance to solvents, etc., in a well-balanced state.

The following sections will be given at examples of successful application of HUM for other oligomeric systems. 


\section{HYDROXYURETHANE COMPOUNDS FROM RENEWABLE PLANT-BASED RAW MATERIALS}

Worldwide potential demands for replacing petroleum-derived materials with renewable plant-based ones in production of valuable materials are quite significant from the social and environmental viewpoints. Native oils and fats are the most important renewable raw materials for the chemical industry. During the last few years modern synthetic methods have been applied extensively to fatty compounds for the selective functionalization of the alkyl chain and gave a large number of novel fatty compounds from which interesting properties are expected $[18,19]$. One of the most interesting derivatives of unsaturated fatty compounds is epoxidized triglyceride oils (ETO), particulary epoxidized soybean oil (ESBO). Until now, ESBO is primarily used as plasticizers for polyvinyl chloride, chlorinated rubber and polyvinyl emulsions to improve their stability and flexibility [19]. Also there are numerous useful derivatives of ETO. Among the various materials, products of reactions of ETO and carbon dioxide $\left(\mathrm{CO}_{2}\right)$ deserve special attention. Point is that composites on the base of epoxidized vegetable oils curable by hardeners [20] or under the influence of irradiation [21] are well known. However, commercially available ESBO could not be used for the room temperature cured compositions since symmetrically substituted epoxy groups are not reactive with aliphatic amines under ambient temperature. A onestep reaction of ESO with carbon dioxide eliminates those problems. The soybean oil containing cyclic carbonate groups is easily soluble in epoxy resin and can readily react with aliphatic amine hardeners. Stages of upgrading of ESBO to value-added NIPUs through the coupling with $\mathrm{CO}_{2}$, followed by the reaction with amine are illustrated in Figure 3.

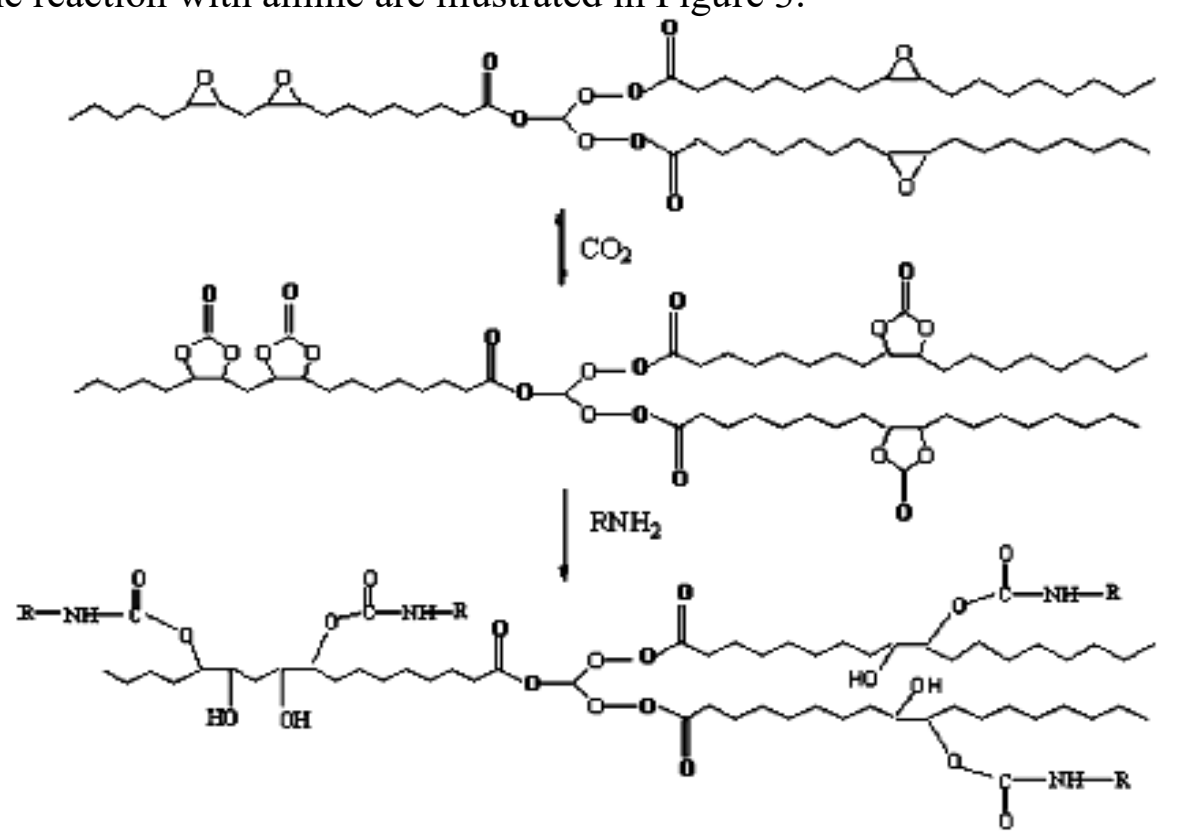

Fig. 3. Cycloaddition of carbon dioxide into ESBO and subsequently aminolysis of CSBO with primary amines.

There are some works dedicated to methods of obtaining of carbonated triglyceride oils (CTO) and composite materials on the base of its.

Reaction of epoxidized soybean oil with carbon dioxide under atmospheric pressure using tetrabutylammonium bromide as a catalyst to conduct the reaction and achieved a conversion of $94 \%$ after $70 \mathrm{~h}$ was demonstrated by Wilkes and co-workers [22]. Furthermore, CSBO could easily react with di- or triamines to produce nonisocyanate polyurethane networks. 
Most recently, Doll et al. reduced the reaction time by $1 / 3$ using supercritical carbon dioxide and 100\% conversion of ESBO into CSBO was obtained after $40 \mathrm{~h}$ [23]. They have also demonstrated a catalyst removal method for system based on the simple Hofmann elimination reaction, reducing the need for organic solvent extraction. However, the rigorous operating condition is energy-consuming and potentially dangerous. In addition, Parzuchowski et al. reported the synthesis of CSBO using KI coupled with 18 -crown- 6 as catalyst at $130{ }^{\circ} \mathrm{C}$ under 6 MPa for a couple of days [24]. The CSO was used for modification of bisphenol-A based epoxy resin.

The composition epoxide-cyclic carbonate was cured using polyamine hardeners by onestep and two-step procedures. All cured compositions were characterized for their thermal and mechanical properties and compared with the parent epoxy network. The optimal properties were obtained for compositions containing CSO and cured by one-step method when phase separation takes place. The mechanical properties were discussed in terms of morphology observed by SEM. At the same time the expensive catalyst along with long reaction time could make the synthesis of CSBO economically unfavorable. It appears that more efforts are needed to consummate this synthetic process.

In the works of Kang, $\mathrm{Li}$ et al. [25] CSBO was prepared by the reaction of epoxidized soybean oil (ESBO) with carbon dioxide $\left(\mathrm{CO}_{2}\right)$ using a novel composite catalyst comprising $\mathrm{SnCl}_{4}$ $5 \mathrm{H}_{2} \mathrm{O}$ and tetrabutylammonium bromide $(\mathrm{TBABr})$. The evolution of the reaction process and structure of CSBO were studied by means of IR, ${ }^{1} \mathrm{H}-\mathrm{NMR}$, and GPC techniques.

Effects of catalyst formulation and various reaction conditions on the reaction were examined. The activity of these catalysts increased in following order: $\mathrm{SnCl}_{4} \cdot 5 \mathrm{H}_{2} \mathrm{O} / \mathrm{TBABr}(2: 1)$ $<\mathrm{SnCl}_{4} \cdot 5 \mathrm{H}_{2} \mathrm{O} / \mathrm{TBABr}(1.5: 1.5)<\mathrm{SnCl}_{4} \cdot 5 \mathrm{H}_{2} \mathrm{O} / \mathrm{TBABr}(1: 5)<\mathrm{SnCl}_{4} \cdot 5 \mathrm{H}_{2} \mathrm{O} / \mathrm{TBABr}(1: 2)<$ $\mathrm{SnCl}_{4} \cdot 5 \mathrm{H}_{2} \mathrm{O} / \mathrm{TBABr}(1: 4)<\mathrm{SnCl}_{4} \cdot 5 \mathrm{H}_{2} \mathrm{O} / \mathrm{TBABr}$ (1:3). In particular, ESBO conversion of $89.2 \%$ was reached when the ratio was $1: 3$. The results showed that the obvious improvement in ESBO conversion using the present composite catalyst under mild conditions was achieved. Moreover, it was interesting to note that very high purity of CSBO was not a prerequisite for the synthesis of NIPUs with good performance.

Polyurethanes by a nonisocyanate route were prepared by reacting carbonated soybean oil with different diamines [26]. The effect of amine structure and carbonate to amine ratio on polyurethane structure and mechanical, physical, and swelling properties was studied. The reactants 1,2-ethylenediamine, 1,4-butylenediamine, and 1,6-hexamethylenediamine were used with the carbonate to amine ratio of $1: 0.5,1: 1$, and $1: 2$. It was found that along with urethane formation, the amine group reacted with ester groups to form amides.

All amines produced elastomeric polyurethanes with glass transitions between 0 and 40 ${ }^{\circ} \mathrm{C}$ and hardness between 40 and 90 Shore A. The reaction of epoxidized soybean oil with carbon dioxide was optimized resulting in complete conversion of epoxy to cyclic carbonate groups ending in polyurethanes with higher crosslinking density and much higher tensile strength than previously reported for similar polyurethanes. Swelling in toluene and water depended on crosslinking density and the polarity of polyurethane networks controlled by the cyclic carbonateto-amine-ratio.

There are recent publications from other research centers on the subject. Thus, researchers at the Institute of Macromolecular Chemistry at the University of Freiburg investigate soy- and linseed oil-based polyurethanes prepared by curing carbonated soybean (CSBO) and linseed (CLSO) oils with different diamines. Later thay have reported on a very versatile new route to linear as well as cross-linked terpene-based non-isocyanate poly(hydroxyurethanes) (NIPU) and prepolymers derived from the novel cyclic limonene dicarbonate (CL) [27]. The catalytic carbonation of epoxidized limonene with $\mathrm{CO}_{2}$ was monitored in the presence of both 
homogeneous tetrabutylammonium bromide (TBAB) and heterogeneous silica supported 4pyrrolidinopyridinium iodide $\left(\mathrm{SiO}_{2}-(\mathrm{I})\right)$ catalysts .

The systematic variation of catalyst type, $\mathrm{CO}_{2}$ pressure and temperature enabled quantitative carbonation in bulk and incorporation of $34.4 \mathrm{wt} . \% \mathrm{CO}_{2}$ into $\mathrm{CL}$. In contrast to conventional plant-oil-based cyclic carbonates, such terpene-based cyclic carbonates afford much higher $\mathrm{CO}_{2}$ fixation and do not contain ester groups.

The absence of ester groups is essential to prevent side reaction during amine cure such as ester cleavage and amide formation, impairing network formation and causing emission of low molecular weight polyols which can plastify NIPU. Novel linear NIPU und prepolymers were obtained by means of CL advancement with diamines such as 1,4-butane diamine (BDA), 1,6hexamethylene diamine (HMDA), 1,12-dodecane diamine (DADO) and isophorone diamine (IPDA).

Research group of the University of Bordeaux studied of supercritical carbon dioxide/vegetable-based epoxidized oils mixtures and fixation of $\mathrm{CO}_{2}$ catalyzed by ionic liquids. Received cyclic carbonates were considered as polyhydroxyurethane precursors [28].

Researches from Reutlingen University and University of Natural Resources and Life Sciences of Vienna obtained a new bio-based non-isocyanate urethane by the reaction of a cyclic carbonate synthesized from a modified linseed oil and an alkylated phenolic polyamine (Phenalkamine) from cashew nut shell liquid.

The incorporation of functional cyclic carbonate groups to the triglyceride units of the oil was done by reacting epoxidized linseed oil with carbon dioxide in the presence of a catalyst. Structural changes and changes in molar mass during the carbonation reaction were characterized. Also the aminolysis reaction of the cyclic carbonate with phenalkamine was monitored, as well as the viscoelastic properties of the system and the time of gelation [29].

Recently authors propose a new method of producing a hybrid polyhydroxyurethane network comprising [30]:

(a) reacting epoxidized unsaturated fatty acid triglycerides with carbon dioxide in the presence of a catalyst to obtain carbonated-epoxidized unsaturated fatty acid triglycerides, wherein conversion of oxyrane groups to 2-oxo-1,3-dioxolane groups (cyclic carbonate groups) for said carbonatedepoxidized unsaturated fatty acid triglycerides ranges from $35 \%$ to $85 \%$; (b) mixing and reacting the carbonated-epoxidized unsaturated fatty acid triglycerides with a compound having an amine functionality comprising at least one primary amine group realized at stoichiometric or within nearly balanced stoichiometry; (c) mixing and reacting the product of (b) with a compound having amine functionality comprising at least two primary amine groups realized at excess of an aminefunctional compound; (d) mixing the product of (c) with a compound having amino-reactive groups and selected from the group comprising: (i) a compound having epoxy functionality, and (ii) a mixture of the compound having epoxy functionality with carbonated-epoxidized unsaturated fatty acid triglycerides, a ratio of the sum of amino-reactive groups to the sum of amine groups being stoichiometric or within nearly balanced stoichiometry; and (e) curing the resulting composition at ambient temperature.

The proposed method can significantly reduce the time of synthesis and improve the quality of the final products. 


\section{SILICON-CONTAINED AND NANO-STRUCTURED HYDROXYURETHANE COMPOUNDS}

The concept of generating silica from alkoxysilanes by the sol-gel method within a macromolecular organic phase (in situ) is widely known in the art. The organic and inorganic components of these materials are present as co-continuous phases of a few nanometers in lateral dimensions [31].

The synthesis of epoxy - amine sol-gel organic-inorganic materials is sufficiently flexible to allow fabrication of a wide group of hybrids with different structures and properties, whose applications range from non-linear optics to adhesive and protective coatings [32].

For coating compositions amine- and/or glycidyl-functional alkylalkoxy silanes (siloxanes) are used as rule. The so-formed epoxy polysiloxane composition provides improved properties of weatherability and chemical and corrosion resistance when compared with conventional nonsiloxane-containing epoxy resin compositions. While such epoxy siloxane coating composition provides improved performance properties (see, for example [33,34]), this composition is known to be somewhat brittle and therefore lacking the desired degree of impact, flexibility, and abrasion resistance for certain applications.

Also, in all cases described above, the compositions include mixtures of epoxy resins, amine hardeners, and functional silanes and/or polysiloxanes in the presence of water and in an amount sufficient to bring about substantial hydrolytic polycondensation of the silane.

Well known in the art are products of reactions of aminoalkyl alkoxyalkylsilanes and cyclic carbonates as intermediate for conventional polyurethanes production. Silicon-containing urethane diols and polyols for subsequent receiving of carbamate-linked block copolymers were designed by some patents [5].

In the paper [35], environmentally friendly polyurethane-silica nanocomposite coatings were described. The silica particles about $150-200 \mathrm{~nm}$ in size were prepared successfully. In addition, the synthesis of cyclic carbonate functional alkoxysilane (4-((3(trimethoxysilyl)propoxy) methyl)-1,3-dioxolan-2-one, CPS) was reported firstly in this paper. CPS was used to modify the surface of silica particles and used as a coupling agent to improve the compatibility of the organic phase and silica particles.

The nonisocyanate based polyurethane/silica nanocomposite coatings based on cyclic carbonate functional soybean oil and polypropylene glycol resins were prepared and their coating performance was investigated. No demage was observed in the impact strength of the coatings. The gloss of CSBO based coatings, decreased steadily with increasing silica content and it was attributed to the compatibility problem between inorganic and organic phases. Moreover with the addition of CPPG into the formulation, the problem on gloss was solved.

The DSC studies also demonstrated that CSBO and CPPG segments are compatible and has a single $\mathrm{T}_{\mathrm{g}}$ around $13{ }^{\circ} \mathrm{C}$. The morphology studies indicate cyclic-carbonate modified silica nanoparticles could be dispersed in CPPG-containing formulations better than soybean oil based formulations and in this way the thermal, mechanical, and coating properties of CSBO-CPPG based PU/silica nanocomposite coatings are improved as well.

Last Japanese patent applications describe various compositions and methods of obtaining Si-contained NIPU [36].

Thus, were disclosed a 5-membered cyclic carbonate polysiloxane compound and process for their producing, which comprises reacting an epoxy-modified polysiloxane compound with carbon dioxide; a polysiloxane-modified polyhydroxy polyurethane resin being derived from a reaction between a 5-membered cyclic carbonate polysiloxane compound and an amine compound, and its production process; polysiloxane-modified polyhydroxy polyurethane resin 
derived from a reaction between a 5-membered cyclic carbonate compound and an aminemodified polysiloxane compound, and its production process.

A cyclic carbonate-modified silane or siloxane can be obtained through addition reaction between an organohydrogensilane or organohydrogensiloxane having a silicon-bonded hydrogen atom ( $\mathrm{SiH}$ group) and a cyclic carbonate having a carbon-to-carbon double bond [37]. The addition reaction is desirably effected in the presence of a platinum or rhodium catalyst. Suitable catalysts used herein include chloroplatinic acid, alcohol-modified chloroplatinic acid, and chloroplatinic acid-vinyl siloxane complexes.

A co-catalyst or $\mathrm{pH}$ adjusting agent such as sodium acetate or sodium citrate may be added. The amount of the catalyst used is a catalytic amount, preferably up to $50 \mathrm{ppm}$, and more preferably up to $20 \mathrm{ppm}$ of platinum or rhodium based on the total weight of the $\mathrm{SiH}$ groupcontaining siloxane and vinyl ethylene carbonate.

The authors have studied new types of NIPUs based on cyclic carbonate-epoxy resin systems and aminoalkoxysilanes [38]. The proposed dendro-aminosilane hardeners give the possibility for the introduction of siloxane fragments into the aromatic structure of BPA epoxyamine and cyclocarbonate network polymers which improves the service properties of the network polymer. Additional hydrolysis of organosilane oligomers creates a secondary nano-structured network polymer.

A nanostructured hybrid liquid oligomer composition including at least one epoxyfunctional component (A), at least one cyclic carbonate component (B), at least one aminefunctional component (C), and, optionally, at least one acrylate (methacrylate) functional component (D), wherein at least one epoxy, amine or acrylate (methacrylate) component contains alkoxysilane units was described in patent application [39].

The composition is highly curable at low temperatures (approximately 10 to $30{ }^{\circ} \mathrm{C}$ ) with forming of nanostructure under the influence of atmospheric moisture and the forming of active, specific hydroxyl groups by reaction of cyclic carbonates with amine functionalities. According to the present invention, the cured composition has excellent strength-stress properties, adhesion to a variety of substrates, appearance, and resistance to weathering, abrasion, and solvents.

\section{SPRAYABLE FOAM}

A basic composition and a technique for mixing and foaming were developed for insulating foam applied by spraying, the material being based on the use of the synthetic raw materials. A standardized procedure for obtaining polyurethane foams was approved.

Technical specifications of this newly developed composition correspond to mean values of a similar urethane-based thermal insulation (the ultimate strength of the new material is about 1.5 times higher than that of the polyurethane foam, and the heat-insulating properties are at the same level as in polyurethane foam with open pores). Possibility of application by spraying was tested on a simulating equipment.

Recently the composition of the foam was studied by the use of renewable raw materials, including new HUM. As a result, hard and elastic foams were obtained with propertied not inferior to polyurethane foams. The foams were produced in the laboratory only (Table 2). 
Table 2. Development of new foams is expedient and can be continued.

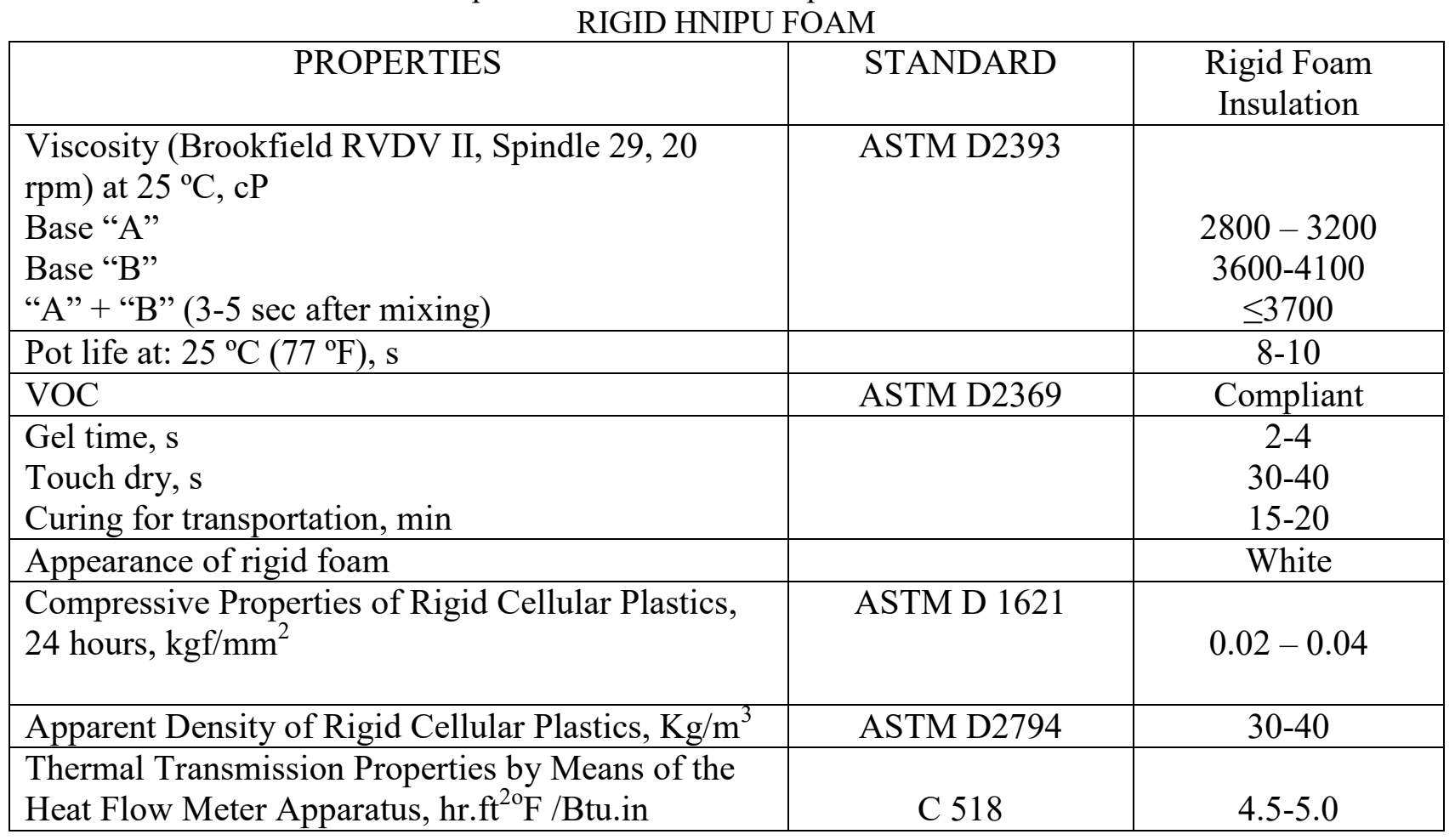

\section{UV CURABLE HNIPU FLOORINGS AND COATINGS}

The photochemistry involved in UV curable materials is very complicated and usually is tailored to the specific process with its method of application, UV source, pigments and desired properties of the cured material.

UV-curable concrete floor coatings provide a durable, high-performance and eco-friendly solution. These thin-film coating systems cure instantly, thereby minimizing the downtime of any facility. Other benefits of these coatings include excellent chemical resistance, easy cleanability, little odor, and the ability to coat in cold conditions.

The surface preparation and applying of UV coatings is similar to that of traditional concrete floor coatings. UV coating systems include both clear and pigmented systems. The clear system consists of a primer and a topcoat which is available in different finishes ranging from high gloss to matte. The topcoat finish can be further enhanced by broadcasting additives for decorative or performance purposes.

Single-coat systems are also available. The thin film thickness can range between 0.3 and $0.8 \mathrm{~mm}$.

Unlike conventional UV-curable coating, formulations developed by our company contain up to $60 \%$ of vegetable oils derivatives, such as modified soybean oil. This allows to obtain a composition of higher elasticity while maintaining the basic strength characteristics.

The use of our compounds improves the adhesion of the cured composition to concrete, allows to reduce the number of coating layers to two, and for special coatings even to a single layer. The uniqueness of this compound is the possibility to apply one layer up to $0.8 \mathrm{~mm}$ thickness, at the rate of polymerization which allows the use of standard curing technology and standard equipment. 
The introduction of our new hydroxyurethane modifier (HUM) based on vegetable raw materials, and adducts obtained on its basis, allow to improve hardness and wear resistance, while maintaining the other properties of the system (Table 3 ).

The uniqueness of the developed formulation and the possibility of coating concrete sometimes without a primer, with layer thickness of 0.3-0.8 mm allow the covering of even open areas. Application is done by spraying, eliminating the negative effects of sunlight during the coating process and uses sunlight during the curing process, which reduces the total polymerization time even more.

Table 3. Properties of HNIPU UV-cured flooring compared to conventional UV-cured flooring

\begin{tabular}{|l|c|c|c|}
\hline \multicolumn{1}{|c|}{ Properties } & Standard & $\begin{array}{c}\text { Conventional UV- } \\
\text { cured flooring }\end{array}$ & $\begin{array}{c}\text { HNIPU UV-cured } \\
\text { flooring }\end{array}$ \\
\hline Adhesion & $\begin{array}{c}\text { ASTM D 3359-07; } \\
\text { Test Method B }\end{array}$ & $3 \mathrm{~B}$ & $5 \mathrm{~B}$ \\
\hline Pencil hardness & ASTM D 3363-05 & $3 \mathrm{H}$ & $4 \mathrm{H}$ \\
\hline Solvent resistance & ASTM D5402-06 & $200+$ & $200+$ \\
\hline Gloss & ASTM D 523 & 84 & 100 \\
\hline $\begin{array}{l}\text { Abrasion resistance, } \\
\text { CS-17, 1000 grams, } \\
1000 \text { cycles, mg }\end{array}$ & ASTM D1044 & $150-200$ & $0.3-0.8$ \\
\hline $\begin{array}{l}\text { Thickness applied, } \\
\text { mm }\end{array}$ & & $0.065-0.1$ & $\begin{array}{c}\text { Not required for } \\
\text { properly prepared } \\
\text { substrates }\end{array}$ \\
\hline Primer & & Required & 1 \\
\hline
\end{tabular}

\section{CONCLUSIONS}

During 2012 year were provided the following works:

1. Elaboration of PI5W black.

2. Testing of epoxy ER-0164; ER215 instead of DER 331.

3. Elaboration of Uramine 5851; Uramine 4761.

4. Elaboration of PI9W Black (indoor).

5. Elaboration of PIO15W Black.

6. Investigation of resistance of FLI4W and FLIO6W in 50\%-70\% $\mathrm{H}_{2} \mathrm{SO}_{4}$.

7. Elaboration of technology of FLI3 Clear.

8. Technology of FLI4W FC Clear.

9. Elaboration ULS FLIO6W clear; FLIO6W grey.

10. Elaboration of PIO15W clear (varnish); PIO15W grey.

11. Elaboration formulation FLI4W with modified vegetable oils (Foam).

12. Preparing samples of different HNIPU adhesives.

13. Preparing different samples of HNIPU materials for testing (150 samples to 50 companies).

14. Elaboration of UV curable green coating. 
15. Introduction of the technologies of HNIPU floorings, Uramines and testing at company "Arpadis", Belgium (Toll manufactures).

16. Elaboration of anticorrosion paints, based on HNIPU.

17. Testing at KLB UV resistance of HNIPU flooring.

18. Testing of non-amine hardeners for oligomer compositions.

19. Testing of waterborne HNIPU compositions.

For further developments in the field of polyhydroxyurethanes, we believe the most appropriate the following directions:

1. Creation of production of polyfunctional cyclocarbonates, development of optimal technology and equipment:

- carbonized vegetable oils and terpenes;

- carbonized aliphatic compounds, including chlorinated ones;

- carbonized polyfunctional silicones.

2. Development of waterborne HNIPU formulations.

3. Development of NIPU formulations for sealants and adhesives.

4. Development of production of amines modified with hydroxyurethane groups.

5. Elaboration of non-amine RT curing agents for oligomer compositions.

6. Development of self-extinguishing compositions of HNIPU.

7. Development of silicone-based HNIPU.

8. Development of NIPU and HNIPU-based foams.

9. Development of formulations for UV-cured compositions.

\section{REFERENCES}

[1] Thomson T. Polyurethanes as specialty chemicals: principles and applications. CRC Press, 2005, 190 pages.

[2] Meier-Westhues U. Polyurethanes: coatings, adhesives and sealants. Vincentz Network GmbH \& Co KG, Hannover, 2007, 344 pages.

[3] Figovsky O. Thesis, Moscow Civil Engineering Institute, 1971.

[4] Figovsky O., Shapovalov L., Encyclopedia of Surface and Colloid Science, ed. P. Somasundaran, V. 3, 1633-1653. N.Y., Taylor \& Francis, 2006.

[5] Leykin A., Beilin D., Birukova O., Figovsky O., Shapovalov L., Scientific Israel - Technological Advantages 11 (3-4) (2009) 160-190

[6] Guan J., Song Y., Lin Y., Yin X., Zuo M., Zhao Y., Tao X. and Zheng Q., Ind. Eng. Chem. Res. 50 (2011) 6517-6527

[7] Rappoport L.Ya., Petrov G.N., Trostyanskaya I.I., Gavrilova O.P. Inter. Polymer Sci. Technol. 8 (5), (1981) T/68-T/70

[8] Yagund E.M., Maklakov L.I., Stroganov V.F., Savchenko V.N., J. Appl. Spectroscopy 45 (1) (1987) 737-741 
[9] Tomita H., Sanda F. Endo T., J. Polymer Sci. A 39 (2001) 851-859

[10] Bernard J.-M. US Patent 8,017,719, 2011; US Patent Application 2011/0288230, 2011.

[11] Moeller T., Kinzelmann H.-G., US Patent 8,118,968, 2012.

[12] (a) Muller-Frischinger I., US Patent 8,003,737, 2011;

(b) Muller-Frischinger I., Gianini M., Volle J., US Patent 8,263,687, 2012.

[13] Diakoumakos C.D., http://appft.uspto.gov/netacgi/nph

Parser?Sect $1=$ PTO $2 \&$ Sect $2=$ HITOFF $\& p=1 \& \mathrm{u}=\% 2$ Fnetahtml $\% 2$ FPTO $\% 2$ Fsearch bool.html\& $\mathrm{r}=1 \& \mathrm{f}=\mathrm{G} \& \mathrm{l}=50 \& \mathrm{co} 1=\mathrm{AND} \& \mathrm{~d}=\mathrm{PG} 01 \& \mathrm{~s} 1=$ Kotzev $\& O S=$ Kotzev $\& \mathrm{RS}=\mathrm{Kotzev}-$ h0http://appft.uspto.gov/netacgi/nph-

Parser?Sect $1=$ PTO $2 \&$ Sect $2=$ HITOFF $\& p=1 \& u=\% 2$ Fnetahtml $\% 2 F P T O \% 2 F$ search-

bool.html\&r=1\&f=G\&l=50\&co1=AND\&d=PG01\&s1=Kotzev\&OS=Kotzev\&RS=Kotzev $-\mathrm{h} 2$

Kotzev D.L., US Patent 8,143,346, 2012.

Diakoumakos C.D., http://appft.uspto.gov/netacgi/nph-

Parser?Sect $1=$ PTO2 \&Sect $2=$ HITOFF $\& p=1 \& u=\% 2$ Fnetahtml $\% 2 F P T O \% 2 F$ search bool.html\&r=1\&f=G\&l=50\&co1=AND\&d=PG01\&s1=Kotzev\&OS=Kotzev\&RS=Kotzev h0http://appft.uspto.gov/netacgi/nph-

Parser?Sect $1=$ PTO2 \&Sect $2=$ HITOFF $\& p=1 \& u=\% 2$ Fnetahtml $\% 2 F P T O \% 2 F$ searchbool.html\&r=1\&f=G\&l=50\&co1=AND\&d=PG01\&s1=Kotzev\&OS=Kotzev\&RS=Kotzev $-\mathrm{h} 2$ Kotzev D. L., US Patent Application 2012/0149842, 2012.

[14] Klopsch R., Lanver A., Kaffee A., Ebel K., Yu M., US Patent Application 20110306702, 2011.

[15] Mecfel-Marczewski J., Walther B., Mezger J., Kierat R., Staudhamer R., US Patent Application 20110313177, 2011.

[16] Birukov O., Beilin D., Figovsky O., Leykin A., Shapovalov L., US Patent Application 2010/0144966, 2010.

[17] Birukov O., Figovsky O., Leykin A., Shapovalov L., US Pat. 7989553 B2, 2011.

[18] Biermann U., Friedt W., Lang S., Lühs W., Machmüller G., Metzger J.O., Klaas M.R.G., Schäfer H.J., Schneider M.P., Angew. Chem. Int. Ed. 39 (13), (2000) 2206-2224

[19] Sharma V., Kundu P.P., Prog. Polym. Sci. 31 (11), (2006) 983-1008

[20] Liu Z.S., Erhan S.Z., Akin D.E., Barton F.E., J. Agric. Food Chem. 54 (6), (2006) 2134-2137

[21] Crivello J. V., Narayan R., Chem. Mater. 4 (1992) 692-699

[22] Tamami B., Sohn S., Wilkes G. L., J. Appl. Polym. Sci. 92 (2), (2004) 883-891; Wilkes G. L., Sohn S., Tamami B., US Pat. 7045577, 2006.

[23] Doll K.M. and Erhan S.Z., Green Chem. 7 (12), (2005) 849-854; Doll K.M. and Erhan S.Z., J. Agric. Food Chem. 53 (24), (2005) 9608-9614

[24] Parzuchowski P. G., Jurczyk-Kowalska M., Ryszkowska J., Rokicki G., J. App. Polym. Sci. 102 (3), (2006) 2904-2914 
[25] Li Z., Zhao Y., Yan S., Wang X., Kang M., Wang J., Xiang H. Catal Lett. 123 (3-4), (2008) 246-251;

Kang M., Zhao Y., Li Z., Wang J., Wang X., CN Patent Application No. 1880360A, 2006; Kang M., Li Z., Zhao Y., Wang J., Wang X., CN Patent Application No.101260232A, 2008

[26] Javni I., Hong D.P., Petrović Z.S., J. Appl. Polym. Sci. 108 (6), (2008) 3867-3875

[27] Bähr M., Mülhaupt R., Green Chem. 14, 2, (2012) 483-489;

Bähr M., Bitto A., Mülhaupt R., Green Chem. 14, 5, (2012) 1447-1454

[28] Foltran S., Maisonneuve L., Cloutet E., Gadenne B., Alfos C., Tassaing T., Cramail H., Polym. Chem. 3, 2, (2012) 525-532;

Foltran S., Maisonneuve L., Cloutet E., Cramail H., Gadenne B., Alfos C., Tassaing T., 10th International Symposium on Supercritical Fluids (ISSF 2012), San Francisco, CA, USA, 13-16 May 2012. P-0902;

Foltran S., Alsarraf J., Robert F., Landais Y., Cloutet E., Cramail H., Mereau R., Tassaing T., 10th International Symposium on Supercritical Fluids (ISSF 2012), San Francisco, CA, USA, 13-16 May 2012. P-1602;

Cramail H., Boyer A., Cloutet E., Gadenne B., Alfos C., WO2011061452, 2011.

[29] Mahendran A.R., Aust N., Wuzella G., Müller U., Kandelbauer A., Journal of Polymers and the Environment, Online First ${ }^{\mathrm{TM}}, 28$ June 2012.

[30] Birukov O., Figovsky O., Leykin A., Potashnikov R., Shapovalov L., US Patent Application 20120208967, 2012.

[31] Mascia L., Heath R. J., Ng V. S.Y., J. Appl. Polym. Sci. 94 (3), (2004) 1279-1290

[32] Innocenzi P., Kidchob T., Yoko T., J. Sol-Gel Sci. Technol. 35 (3), (2005) 225-235

[33] Foscante R.E., Gysegem A.P., Martinich P.J., Law G.H., US Pat. 42500074, 1981.

[34] Mowrer R.N., Foscante R.E., Rojas J.L., US Pat. 5618860, 1997; US Pat. 5804616, 1998; Mowrer R.N., Kane J.F., Hull C.G., US Pat. 5942073, 1999.

[35] Türünç O., Kayaman-Apohan N., Kahraman M.V., Menceloğlu Y., Güngör A., J Sol- Gel Sci Technol. 47 (3), (2008) 290-299

[36] Hanada K. et al. US Patent Applications: 20120232289, 20120237701 and 20120231184 2012.

[37] Nakanishi T., Kashida M., Miyawaki S., US Pat. 7425283, 2008;

Nakanishi T., Kashida M., Miyawaki S., Ichinohe S., Aramata M., US Pat. 7544759, 2009.

[38] Figovsky O., Shapovalov L., Buslov F. Surface Coatings International Part B: Coatings Transactions 88 (B1), (2005) 67-71

[39] Birukov O., Beilin D., Figovsky O., Leykin A., Shapovalov L., US Pat. 7,820,779 B2, 2010. 